\title{
A INDISCIPLINA E A ATUAÇÃO DO GESTOR ESCOLAR
}

\section{ARTIGO ORIGINAL}

NAITZEL, Marli Cristina ${ }^{1}$

NAITZEL, Marli Cristina. A indisciplina e a atuação do gestor escolar. Revista Científica Multidisciplinar Núcleo do Conhecimento. Ano 04, Ed. 10, Vol. 04, pp. 113129. Outubro de 2019. ISSN: 2448-0959, Link de acesso: https://www.nucleodoconhecimento.com.br/educacao/atuacao-do-gestor

\section{RESUMO}

Este trabalho aponta uma reflexão sobre a problemática da indisciplina sob o olhar do gestor, bem como quais as intervenções e ações deste, para amenizar paulatinamente os comportamentos indesejados e consequentemente, bloqueadores de um trabalho escolar que vislumbre o sucesso da escola como parte integrante da comunidade. Inicialmente discute o conceito de indisciplina dentro da concepção familiar, considerando seus aspectos atuais. Ressalta características particulares da indisciplina escolar neste século e a necessidade das intervenções preventivas como formas estratégicas para enfrentar essa questão. Ao final, apresenta algumas considerações sobre a postura do gestor frente ao problema tratado, ressaltando a necessidade de ações compartilhadas entre todos os atores envolvidos.

Palavras-chave: indisciplina, família, escola, gestão educacional.

\section{INTRODUÇÃO}

Uma das ideias definidas com relação à temática da indisciplina, difundida pelo debate público e que dá maior força junto da classe dos educadores, é a de que existe, cada vez mais, problemas de indisciplina nas escolas. Contudo, há que se destacar aqui,

1 Pós-graduada em Psicopedagogia (UNIFIAN-2002) e Graduada em Pedagogia (UNESP-1997). 
que em sua maioria, tais ideias se constroem através da comparação entre a atualidade e o passado, ou seja, são delimitadas pelas visões saudosistas de como a educação e a disciplina aconteciam num passado distante, onde é relevante assinalar que, pertenciam a um outro momento social, histórico e cultural.

O desafio de gerir a indisciplina na escola é hoje, uma das questões mais presentes dentro do contexto escolar. Afinal, vemos com frequência notícias de fatos que envolvem a indisciplina como aspecto basilar das relações professor-aluno e escolaaluno em que em sua maioria, retratam a dificuldade do gestor em lidar com tal assunto na sua prática cotidiana.

Nesse ínterim, urge a ideia de que o gestor, como mediador de diversas situações escolares, seja capaz de gerir a indisciplina escolar visando o sucesso da aprendizagem e da própria atuação dos profissionais que se encontram no contexto escolar, os quais também, carecem de orientações, que partiriam do gestor, de como lidar com a indisciplina dos alunos.

[...] a indisciplina na escola não pode ser vista como existindo em si mesma, como uma qualidade inerente ao próprio comportamento, mas tem antes que ser analisada e compreendida no contexto da relação pedagógica em que a situação emerge e é categorizada enquanto tal. É no contexto da relação pedagógica que o professor categoriza alguém ou algum ato como sendo indisciplinado e, sendo assim, ao mesmo tempo em que emerge a relatividade deste conceito, é todo o contexto pedagógico que aparece implicado na situação e não apenas o sujeito que praticou um dado ato. (CARITA e FERNANDES,1987, p.16).

Buscar-se-á abordar o papel da família no que tange a indisciplina, apontando as condutas e os pensamentos que fazem parte, em sua maioria, da consciência coletiva que os pais possuem sobre limites e sua aplicabilidade no contexto da sociedade em que vivemos.

Após essa análise do papel familiar, busca se destacar as implicações da indisciplina dentro da escola, procurando explanar e rever os papéis e relações dos atores que estão intimamente ligados a essa problemática, em especial, os professores e alunos. 
E por fim, é procurado apontar impasses e perspectivas do como gerir a indisciplina no contexto escolar, sob o prisma de que o gestor deve saber intervir competentemente, ponderando atitudes e delineando caminhos junto com toda a comunidade escolar.

\section{A FAMÍLIA E O SEU PAPEL FRENTE À INDISCIPLINA}

A família é concebida como o primeiro ambiente de socialização da criança. Ela precisa cumprir grande presença nas ações realizadas pelas crianças e adolescentes, porém, as reclamações que trazemos assinaladas é que os alunos vêm para a escola com uma insuficiente noção de respeito e de limite, predominando o conceito de que as crianças saem de suas famílias sem o aprendizado dos valores básicos indispensáveis para participar da sociedade. Julgar-se que a família é o pilar de sustentação do homem, portanto ela é o conceito que a criança tem para formar sua personalidade.

É com seus familiares que a criança tem sua primeira interação social. A criança aprenderá os primeiros valores e regras de convivência social com a mãe, o pai, ou com quem os represente. Assim sendo, uma harmonia familiar se torna essencial para uma personalidade bem construída. Por isso que tal harmonia será o ingrediente principal para que a criança chegue à escola bem receptiva e integrada ao seu recente grupo social, aos professores e colegas.

Mostrar o que é certo e errado, ajudar a construir valores, imprimir limites é uma incumbência da família, elucidando assim aos filhos, que para conviver equilibradamente em sociedade é preciso respeitar as regras existentes de maneira coesa.

Observa-se comumente, que para substituir a carência e afastamento dos filhos em virtude de necessidades de subsistência, determinados pais deixam de cumprir suas responsabilidades de educar, e erroneamente para amenizar essa falta, aceitam uma liberdade exacerbada por parte dos filhos, dando-lhes tudo o que querem. Daí então, as crianças param de compreender que para a realização de suas vontades há limites, 
permitindo-se assim o surgimento da indisciplina. E certamente, quando os filhos não respeitam em casa as regras, não respeitarão regras também na escola e consequentemente na sociedade.

A escola não pode e deve substituir o papel da família. Não querendo dizer com isso que a escola não deva elaborar seus próprios valores sociais, ou valores complementares ao da família, ela deve sim ampliar a experiência de cada aluno através do desenvolvimento do senso crítico, o mútuo aprendizado e uma conduta reflexiva e política.

Portanto, esse seria o padrão correto a ser seguido, entretanto o que se vê é o aumento de alunos que chegam à escola sem noções de limites. Tal fato se deve à incoerência que a mente da maioria dos pais apresenta, a qual os levam a agir com a equívoca certeza de acertar, dando aos filhos tudo o de melhor que podem lhes proporcionar. Um dos motivos dessa confusão é a próprio contexto social vivido por todos nós, no qual os filhos-alunos observam que a maioria dos políticos é corrupta, onde é dado maior valor ao ter do que ao ser, assim como o respeito pelo outro é visto como algo sem importância e a impunidade é tida como natural. Nessa conjuntura, os pais influenciados e confusos, são movidos pela preocupação de mostrar aos filhos os velhos valores, parecendo-Ihes que essa ideia seria a saída mais adequada e "[...] na maioria das vezes a indisciplina na família é resultado de um excesso de zelo, de um esforço tremendo para garantir o bem-estar de seu filho". (TIBA, 1996, p.29).

Vincula-se a esse quadro a influência dos meios de comunicação, a qual não podemos negar que é intensamente poderosa, e incentivam incessantemente ao consumismo e a soma de valores materiais em prejuízo da educação dos reais valores humanos.

Os pais, conscientemente ou não, procuram assegurar um bom futuro aos filhos, e se deparam com uma realidade que os conduzem a indagar os valores passados de geração pra geração. E nessa incerteza os pais acabam por afrouxar a forma de educar os filhos tolerando atitudes dos filhos que repercutirão em faltas indisciplinares e até atos inflacionais. 
As famílias geralmente são responsáveis pelos fracassos dos filhos, "seja pela separação dos pais, por sua ausência, seja por defeitos morais e psíquicos que Ihe são frequentemente atribuídos". Geralmente são tidos como sexualmente promíscuos, primitivos, vadios, pouco inteligentes, violentos, com vocação para marginalidade e delinquência. (KRUPPA, 1994, p.107)

Nesse bojo, faz-se necessário que os pais compreendam de forma muito clara que para exigir a disciplina dos filhos há que se seguir um conhecimento das características de cada faixa etária, para assim tornarem-se coesas as exigências a serem feitas no transcorrer do crescimento dos filhos. Assim, os pais ao buscarem uma imposição firme e amorosa no lar, conseguindo respeitar o fato dos filhos estarem em formação e dando limites aos mesmos, conquistarão mais sucesso, afinal, há que se vislumbrar um equilíbrio, deixando de agir para com o filho ou só com condescendência permanente ou só com autoritarismo excessivo.

Portanto, dialogar com o filho para se atingir um acordo e cuidar para que as cobranças familiares quanto a horários e limites sejam exercidas. Contudo, o que vemos, muitas vezes, são pais que incentivam atitudes contrárias, pois assim abdicam-se da atenção e exigência constantes por parte dos filhos. Esse quadro acaba surtindo consequências desastrosas, pois quando os pais se valem das fontes de entretenimento (vídeo game e TV), estimulam o consumismo dos filhos, e estes, sem carinho, sem atenção e sem orientação, sentem-se sozinhos e daí lhes são oportunizadas situações para realizarem atitudes mais graves, para as quais os pais fingem-se de surdos.

A indisciplina se faz presente no desrespeito do desenvolvimento biológico por parte dos pais motivados pelo amor, pelo desejo de satisfazer todas as necessidades dos filhos, alguns pais não modificam seus comportamentos e ofertas a medida que a criança cresce. (TIBA, 1996, p. 27).

Na maioria das vezes quando os professores e a escola solicitam a presença dos pais, estes afirmam e aprovam o uso de castigos dos quais foram vítimas quando estudavam (escola tradicional), ou até, dependendo da falta do filho pedem ajuda a polícia, ao Conselho Tutelar como esperança de que a justiça Ihes ofereça uma solução. 
O ato indisciplinar das crianças é, comumente, o resultado da ausência que elas sentem dos pais, pois atualmente, com a correria do dia-a-dia, o tempo que as famílias dedicam aos filhos é ínfimo. Isso faz com que os filhos busquem a atenção dos pais a qualquer preço, perpassando desde as brigas dentro de casa até os comportamentos de revolta para com as pessoas dentro da escola.

Interessante notar que os pais jovens, que possuem filhos no ensino fundamental, apresentam estreito preparo para o cumprimento das responsabilidades que os compete, devendo-se isso ao fato de que possuem um contexto familiar adverso do tradicional, ou seja, pais que são solteiros e que não planejaram desempenhar esse papel naquele determinado momento, acabam por não ter maturidade e entusiasmo para comprimirem com as responsabilidades que Ihes são atribuídas. De acordo com Içami Tiba (2003), se os pais forem omissos e ficarem quietos por medo de perder o amor do filho, correm o risco de serem menosprezados e ignorados.

Um bom número de pais acaba delegando a outras pessoas sua função do ato de educar, convergindo-se aí a razão das queixas provindas das escolas, as quais acusam a família pelo comportamento inadequado dos filhos.

Nessa mesma perspectiva, há pais que censuram a atitude de professores disciplinadores e exigentes e estes mesmos pais precisariam se conscientizar de que não estão desempenhando sua legitimidade de pais educadores.

A família deveria propiciar condições para formação de uma estrutura psicológica moral capaz de preparar esse aluno para conviver em ambientes regrados. Isso só reforça a relação que se estabelece entre o comportamento indisciplinado do aluno e sua formação moral; indicando, portanto, que a raiz do problema está, também no tipo de educação moral que as crianças vêm recebendo. (LA TAILLE, 1996, p. 23)

O que colabora enormemente para o exercício ético de conduta, é a disciplinar dentro de um ambiente de diálogo, justiça e segurança, o qual deve ser cultivado na rotina das famílias, pois estabelecer e zelar por regras adequadas de vida é um ato de amor. Através desse panorama é que se é possível da criança aprender desde cedo a ter persistência, autocontrole e tolerância frente às frustrações. Dessa maneira, quando 
as crianças estiverem perante a sociedade, à escola, e encontrarem uma realidade que Ihe impuser limites, não vivenciarão conflitos de convivência.

As confusões presentes na sala de aula, o demasiado caso de conflitos, desordem emocional, ausência de interesse, respeito etc. comprovam esta passagem de responsabilidade sobre a educação dos filhos para a escola. Podemos deduzir que mesmo as crianças originárias de lares afetados, cujo ambiente é necessitado de incentivos e orientações adequadas, terão condições de ultrapassar estas crises, caso haja oportunidade de praticar, em outros ambientes educativos, um exemplo diferente de educação e podem até, unidos com os pais, obterem comedimento e apoio.

Neste rumo a escola, concebida como um lugar que possibilita uma convivência social diferente do quadro familiar, tem um importante papel, que não o de contrabalançar privações afetivas, culturais e sociais do aluno, mas sim de apresentar a oportunidade de este ter acesso a experiências e informações novas e provocadoras, capazes de provocar mudanças e gerar novos processos de comportamento e desenvolvimento. Todos sabemos que algo precisa se modificar nas práticas da educação. Assumimos novas metodologias e, traçamos novos objetivos, e entre o que sabemos e a nossa perspectiva de resultados, localiza-se uma lacuna, um espaço que deve ser completado pela nossa atuação. Não um paradigma de ação fechado, pois seria limitar a competência criadora e o potencial de cada um, mas constituir um possível caminho integrado e maleável que certamente nos transportará a outros resultados, não só durante prática pedagógica, mas na própria história de vida. Este caminho sintetiza-se em Valores Humanos que satisfaçam à convivência do sujeito em seus contextos de ligação, isto é, a exploração de si mesmo e de seu potencial de ação, praticando suas habilidades no seu mundo de ação e a consciência refletindo sua atuação analítica num enfoque global e local.

Certamente, em família é que se deveria iniciar a formação de discernir, respeitar e questionar, onde um equilíbrio fosse forjado, no sentido de nem se silenciar forçosamente como antigamente, nem de afrontar, gritar como hoje. Pois tal formação é o mais válido instrumento para a vida, onde o ideal é se expressar educadamente, tanto com os familiares, como com as outras pessoas. 
No processo ensino aprendizagem, a família é indispensável, sendo importantíssima sua participação na vida escolar (e social) dos filhos. A família é a conexão que capacita o filho a entender e participar adequadamente da prática educativo, promovendo assim o seu desenvolvimento, e também o trabalho da escola.

Deste modo, família e escola podem atingir melhores frutos enquanto parceiras. $\mathrm{O}$ professor cumpre, neste trabalho, um papel de relevante importância, como abordaremos no segundo capítulo.

\section{A INDISCIPLINA NA ESCOLA}

O problema da indisciplina que observamos ao longo da conjuntura pedagógica, nos permite partir rumo a uma reflexão baseada na bibliografia consultada, e que nos faz perceber que na esfera da sala de aula, a indisciplina é dotada de aspectos alheios a ela e que se prevalecem na esfera da sociedade.

Assim sendo, não podemos entender a indisciplina apenas e simplesmente na prática das relações sociais escolares, pois ela vai além deste espaço escolar e dessa maneira, pede um entendimento nas várias esferas das estruturas sociais. (MESQUITA, 2003).

Atualmente, vivemos e numa sociedade em que as instituições criam composições de controles dos indivíduos objetivando a conservação da ordem. Numa sociedade desenhada com um panorama marcado por crises vislumbradas no cenário políticosocial-econômico, impera também a crise da ética e, portanto, também da instauração da indisciplina.

[...] a ampliação da escolaridade obrigatória e o consequente aumento dos alunos em espaços que, por vezes, mal os comportam e se considerarmos a própria evolução das sociedades ocidentais, com seus desequilíbrios sociais e econômicos e suas crises de valores e autoridade que não podem deixar de se refletir na escola. (ESTRELA, 2002, p.28).

$\mathrm{Na}$ esfera econômica política e social assistimos aos avanços tecnológicos e científicos sob a ótica de um afastamento cruel entre ricos e pobres. Presenciamos 
também a crescente disputa dos grupos sociais menos favorecidos, disputa esta que resulta de uma sociedade capitalista que se conforta diante desta realidade favorável aos privilegiados. (MESQUITA, 2003).

Para uma sociedade melhorar é necessário que suas crianças tenham algum idealismo, especialmente quando jovens. É preciso que se incuta nelas um sentido de comunidade e de auto sacrifício. É fundamental que as crianças sejam desafiadas para serem melhores do que são, caso contrário cai-se no império do cinismo, desde muito cedo e não se realiza nada. (DAMON, 1995, p. 60).

No que tange a crise de valores éticos é revelada através dos meios de comunicação quase que cotidianamente, por meio de denúncia de corrupção, de desmandos, de desrespeito aos direitos humanos, de abuso de autoridade etc. Infelizmente, a competição descomedida, passa a ser, portanto, o grande sinal da sociedade moderna. Do mesmo modo, é instalada no país uma cultura de terror e violência, assinalada pelo abuso de poder de representantes de entidades que deveriam assegurar a segurança do cidadão. Tais acontecimentos, longe de serem isolados, vêm colaborando para atmosfera de impunidade que predomina, policiais militares e civis com "regalia" de agredir e tirar a vida de cidadãos de bem.

Todo esse panorama fortalece a apatia do estado moral da busca dos poderosos em favorecer a qualidade de vida do povo, vivificando assim o predomínio dos poderosos. (MESQUITA, 2003)

E é nesse cenário de crises: político, social, e econômico, que está contida a família e a escola e por meio desse mesmo cenário é que a indisciplina se aloja.

Partindo desse raciocínio, é que somos "levados" a compartilhar o conceito de que os alunos são a imagem de uma sociedade opressora, injusta, e a escola se considera impotente diante do aluno, sobretudo dos que se originam de um contexto cultural e economicamente desfavorecido.

Com base nas afirmações supramencionadas notamos que alguns dos professores e especialistas impõem a responsabilidade pelo comportamento indisciplinado do aluno, 
à educação dada pela família, e assim transferem tal problema totalmente à família, isentando a escola. Com relação a essa visão, Lino de Macedo, rebate dizendo que:

[...] disciplina escolar não é questão de boa conduta nem de formação trazida de casa. Disciplina se aprende e é do interesse de todo mundo, porque facilita a relação da gente com as coisas. (MACEDO, 2005, p.47).

Ainda existem outros professores e especialistas que aparentam entender que 0 aparecimento da indisciplina, tanto em maior ou menor grau, no contexto escolar, deriva da personalidade de cada aluno, daí a responsabilidade é atribuída ao próprio aluno.

Tais profissionais compreendem que os aspectos comportamentais de cada aluno são imutáveis, já que são determinados desde o nascimento e que são parte da natureza de cada indivíduo. Logo, ignoram a experiência escolar, concebendo que esta não terá influência nenhuma no comportamento individual.

Assim, estes profissionais, além de legitimar as causas da indisciplina através das proposições acima descritas, também ligam o comportamento indisciplinado às transformações da adolescência e aos problemas intrínsecos à infância. De um modo geral, os adolescentes são questionadores, e a ideia de que não adianta querer lutar contra isto toma força.

Ainda existem alguns professores, comumente os mais antigos, que como também, atordoados com o problema da indisciplina procuram buscar, ainda que de modo superficial, explicações para a existência de tal acontecimento. Habitualmente concebem a indisciplina como uma marca dos tempos modernos, retratando até uma certa nostalgia pelas práticas pedagógicas e sociais de antigamente, as quais não toleravam a desobediência.

Professores, além da precariedade de sua formação e do escasso conhecimento que têm da realidade histórico-social, não têm levado em conta o aluno concreto com o qual lida diariamente. O professor de fato está trabalhando de costas para os alunos (FRANCO, 1986, p. 115). 
Observamos que ainda muitos professores não enterraram as práticas pedagógicas do passado, e apesar de reconhecerem que o paradigma da sociedade se transformou, ainda julgam que a disciplina deva ser coerciva, através dos castigos e ameaças.

No tocante ao disciplinamento produzido na interação professor-aluno, segundo Tragtenberg, a própria disposição das carteiras na sala de aula reproduz relações de poder: o estrado que o professor utiliza, acima dos ouvintes; estes sentados em cadeiras linearmente definidas, próximas a uma linha de montagem industrial, configuram a relação 'saber/pode' dominante/dominado. (KRUPPA, 1994, p.105).

A escola do passado ficou para trás, mesmo este sendo ainda para alguns professores (obsoletos) o modelo desejado. Desse prisma, os professores contemporâneos devem desenvolver habilidades de dinamização, estruturação e criação de condições de aprendizagem, estimulando assim, as capacidades individuais e a autoconfiança dos alunos. (MESQUITA, 2003).

E para tanto, é necessário que o professor seja o agente de promoção do bem-estar na sala de aula, tornando o ambiente harmônico uma via para a conquista da disciplina e organização durante o processo de aprendizagem.

A relação professor-aluno não pode ser pensada abstratamente, como se existisse autonomamente, ou seja, à revelia do conjunto dos fatores externos à escola. Ao contrário, deve ser entendida, de um lado, como parte do planejamento curricular da escola, isto é, da maneira como a escola organiza e desenvolve o seu trabalho pedagógico. (FRANCO, 1986, p. 68).

Podemos dizer que o professor tem que rever e remodelar seu papel, buscando sistematicamente sua formação continuada, atualizando-se e capacitando-se dentro do contexto da sociedade global. É de suma importância, portanto que o professor saiba comprometer-se enquanto educador e possa buscar auxílio na equipe de profissionais da qual faz parte. 


\section{O PAPEL DO GESTOR FRENTE À INDISCIPLINA}

O gestor escolar deve atuar como linha condutora de toda a ação não só no que diz respeito ao ensino aprendizagem, mas também com relação à socialização de todos estão envolvidos nesta ação. Ele precisa ser um participativo e preparado para intervir acerca dos profissionais na organização de conflitos, atuando não apenas como mediador, mas também como motivador, propiciando uma interação natural entre todos, professores, alunos, funcionários e família.

Espera-se do gestor o compromisso de instrumentalizar-se de tal modo que consinta a todos os envolvidos participarem coletivamente, procurando um só ideal, pois assim será delineado um projeto concreto e estável de uma aprendizagem qualitativa. Com relação ao problema da disciplina na escola, assim como também todos os processos que ela provoca, o gestor precisa ser comprometido com sua equipe, sugerindo soluções, as quais devem originar da aberta participação de todos, pois o problema disciplinar é de todos e não se reduz a apenas um profissional.

É imprescindível que o gestor escolar tenha a habilidade de ouvir todos elementos da escola, tanto professores, funcionários e pais de alunos. Na maioria das vezes os alunos não são os únicos errados da situação, existem muitos professores que gritam com alunos sem precisar, e funcionários que acabam debatendo com os pais na entrada da escola, e isso deve ser averiguado e lidado pela direção.

Entretanto, o que acaba acontecendo muitas vezes é que o gestor nem sempre é uma pessoa qualificada para trabalhar com os conflitos e desafios que cabe a ele solucionar como líder.

Os gestores normalmente são escolhidos por razões clientelísticas, transformando-se, dessa forma, em verdadeiros cabos eleitorais de políticos medíocres. De outro lado, esses burocratas da educação passam dias após dias assinando papéis. Pouco sabe de educação, do que se passa na escola e na sala de aula. Ao invés de serem a direção consciente do trabalho coletivo da escola, se transformam em administradores incompetentes da educação. (FRANCO, 1986, p. 51). 
Assim sendo, a escola fica confusa em meio a um mau direcionamento e a uma carência de motivação para a realização consciente da coletividade. Quando o gestor não tem competências para vencer desafios e trabalhar com a equipe, sua ação será um fracasso que repercutirá dentro da escola.

Ainda que bem preparado e sendo um capaz profissional comprometido com seu fazer, ele irá enfrentar desafios que deverão ser superados com toda ética.

No que tange o exercício da disciplina e limite dos alunos, o gestor deve agir com constância e firmeza, atraindo a atenção de todos para a problemática, tendo como certa a decorrência da coletividade e quando preciso for, ser comedido e humilde para pedir a intervenção de outros grupos não só da educação, mas também da comunidade como um todo.

Cabe ao gestor escolar, gerir a indisciplina tendo como pressuposto norteador o fato de que nunca a liberdade de um indivíduo deve ser aplicada em prejuízo do bem-estar da comunidade. E para isso o que deve imperar é uma adaptação entre a traços típicos do aluno e a estrutura educacional. Assim, a disciplina escolar não deve ser um grupo de regras negativas, na verdade, a disciplina deve ser dinâmica, funcional e realizadora, ou seja, deve nascer espontaneamente do trabalho escolar.

Para dirigir uma escola, é preciso ter competência técnica, isto é, saber organizar seu trabalho e o da escola, ter domínio dos conteúdos escolares, desenvolver boas relações humanas e ter espírito de justiça para coordenar, com tranquilidade, professores, alunos e funcionários. (ATTA, 2000, p.31).

Trabalhar limites e disciplina não pode ser uma ação isolada, é um compromisso extensivo a todos, demandando que ideias sejam compartilhadas, configurando-se em tarefa de todos da escola, da família e da sociedade.

É necessária grande sensibilidade da direção em relação aos processos de aperfeiçoamento, principalmente, em relação à inovação da gestão; sistema de valores orientado em termos de objetivos educacionais, sociais e comunitários; interação e comunicação intensivas entre indivíduos e grupos; planificação e ação colaborativa entre atores internos e externos à organização escolar. (GLATTER, 1995, p.148). 
O gestor como líder da escola, é quem verifica a necessidade de trabalhar valores, investindo e incentivando a formação de seus profissionais, estando estes assim habilitados para encarar este problema e procurar parcerias, pois de nada adiantará se ele agir solitariamente, como se a problemática fosse apenas dele.

Do ponto de vista mais prático, o gestor deve estar capacitado para a certeza de que conflitos estão sempre presentes, o que o forçará a trabalhar, a cada momento, com todas as agitações do dia-a-dia, e nessa perspectiva precisa localizar as formas pelas quais tais agitações e turbulências são compostas, fazendo uma ligação entre estas com os limites e as punições da escola. Para tanto, deve sempre manter o olhar direcionado sob suas óticas, a do professor e a do aluno.

No que diz respeito ao professor, o gestor deve apoiar efetivamente $\mathrm{e}$ necessariamente, para que este trabalhe com o aluno conforme as reflexões feitas no capítulo anterior, auxiliando para a interação professor/alunos. Cabendo ao gestor:

[...] Não deixar que se perca a visão de conjunto. Não designar alguém da escola só para cuidar da disciplina; a construção da disciplina é tarefa de todos. Subsidiar, apoiar o professor para que seja o autor da ação educativa, inclusive disciplinar; orientar, ajudar a formar o professor para o diálogo com os alunos. Resgatar o saber docente. Reconhecer que os professores construíram um saber a partir de suas experiências. Só que geralmente é um saber fragmentado e até contraditório. Daí a importância de partilhar, fazer a crítica e sistematizar como cultura pedagógica do grupo. Confiar no grupo; superar o controle, a vigilância como se o professor fosse irresponsável [...] Apoiar as iniciativas de mudança dos professores; isto é sinal de vida. Dar tempo para colocarem prática e analisar. Não frustrar com rigorismo e medo do erro. Pesquisar mais a própria prática; ser capaz de levantar as representações dos professores. No caso aqui, o que pensam a respeito dos problemas de disciplina. Ter mais coragem de ouvir; esta é uma coisa que dificulta o trabalho de direção ou coordenação: os professores vêm com suas queixas; a equipe, com medo de que, com aqueles problemas todos, ele desanime, já começa a tentar dar explicações, justificativas, não os deixando falar até o fim. É preciso confiar mais em nossa capacidade, em nossa proposta, na força do próprio grupo e deixá-los falar tudo o que têm para falar, e só depois disto começar a reconstruir coletivamente. [...] Criar base para um trabalho maior. Superar o formalismo; abrir espaços para que o professor possa atender os alunos em suas necessidades, sejam de aprendizagem ou relacionamento. Apoiar o professor diante da comunidade. Os eventuais 
equívocos serão tratados internamente. Saber enfrentar pressões equivocadas dos pais. É muito desgastante quando o professor sente que seu trabalho não tem o respaldo da equipe. Vejam, isto não significa conivência, acobertar erros, mas profissionalismo, tratar as coisas na hora e local adequado. (VASCONCELOS, 1994, p.250-251).

Com relação ao aluno, quando necessário, o gestor poderá ajudar o professor a averiguar, investigando comportamentos de alunos ou grupo de alunos, partindo das seguintes premissas: Se as queixas que acontecem na escola, também acontecem fora. Se os comportamentos apresentados agora na escola ocorreram antes, ou são novos. Se houve algum acontecimento na escola ou na família que poderia ter motivado tal comportamento. Se o aluno gosta ou não da escola e se o aluno queixase de algo da escola. Assim deve-se entender:

[...] a indisciplina no contexto das condutas dos alunos, dentro ou fora da sala de aula, nas diversas atividades pedagógicas, a dimensão dos processos de socialização e relacionamentos que os alunos exercem na escola e também considerar a indisciplina contextualizada 0 desenvolvimento cognitivo desses alunos. (GARCIA, 1999 p. 102).

Além dessas premissas, o gestor pode se valer do diálogo ou da execução de atividades para levar o aluno a pensar sobre suas atitudes e comportamentos oportunizando the uma transformação de conduta perante a sociedade.

De uma forma mais panorâmica o gestor poderá liderar o planejamento de práticas pedagógicas e organizacionais que levem em consideração os aspectos de cada faixa etária e suas transformações no que tange o desenvolvimento social, psicológico e biológico dos alunos que frequentam as escolas. Com um trabalho sistemático e com o tempo criará na escola uma cultura humanista que, com certeza ajudará as relações interpessoais e sociais.

[...] o conflito surge entre a busca da identidade e a confusão dos papéis. A maturação física indica o início da idade adulta, mas sob outros aspectos o adolescente age ou é tratado como criança. A ambiguidade do papel do adolescente na sociedade provoca confusão. (ERIKSON, 1992, p. 89).

Dentre muitas ações podemos destacar como facilitadores de prática pedagógica: 
- Planejando e executando atividades dirigidas para a valorização do sujeito, priorizando sua autoestima e explorando o potencial de cada aluno, como a criação de oficinas de vídeo, oficinas de teatro e música, de artesanato, etc.

- Concebendo campanhas que focalizem a paz, através de gincanas cooperativas.

- Oferecendo aos alunos a responsabilidade para cuidar e zelar do prédio escolar, oportunizando que estes decorem as salas e demais dependências da escola e assim envolvendo-os, oferecendo-Ihes uma escola que escola tem significado para eles.

- Incentivando a realização de trabalhos em grupos para facilitar a socialização.

- Oportunizando o diálogo cotidiano com a comunidade e assim, valorizando os pais.

- Utilizar a hora do recreio para que este seja prazeroso, valendo-se de jogos dirigidos, músicas ambientes ou demais atividades sugeridas pelos alunos.

Em suma, a indisciplina deve ser vista como um problema a ser enfrentado por todos, professores, funcionários, alunos e pais, que se acham envolvidos no processo da aprendizagem.

Consequentemente é imperioso ter uma gestão escolar participativa, e que seja apta para mexer com a qualidade da escola positivamente, pois quando o gestor escolar participa e busca opiniões de sua equipe e as aproveita para tomar decisões, cria uma atmosfera de aprendizagem mais significativa, cria uma consonância de ações e ideias necessárias para a concretização de qualquer projeto.

\section{CONSIDERAÇÕES FINAIS}

No que tange a questão da indisciplina, os pais apresentam uma grande dificuldade em entender o papel educativo do pensamento do professor, inferindo anseios e responsabilidades com relação à educação de seus filhos. Nessa ótica, a família é vista pelos professores, na maioria das vezes, como omissa, ora por ausência de conhecimento sobre como lidar com seus filhos, ora por fugir da prática de estar 
presente na vida deles, devido ao excessivo trabalho ou a ideia de que outros, talvez a escola, os substitua.

Apesar de toda esta ocorrência de indisciplina dentro da escola, fica evidente que há um olhar superficial e sem muita fundamentação sobre o problema indisciplinar por parte dos envolvidos. O que percebemos é que as complicadas relações entre a escola, a família e a sociedade não parecem ser, de maneira satisfatória, aprofundadas e debatidas. Contudo, a indisciplina é um problema presente que deve ser encarada por todos os envolvidos, de forma coerente e responsável, e não da maneira que comumente acontece, a escola culpando a família, esta a escola, e ambas a sociedade, portanto a transferência da culpabilidade de sua existência é um degrau que deve ser superado, para assim galgarmos um patamar mais elevado e efetivo de comunicação entre essas três esferas: a família, a escola e a sociedade.

Conforme o que foi visto até aqui através dos autores, pode-se entender que a disciplina não diz respeito só à acomodação exterior e expressiva das regras contidas nas regulamentações escolares, pelo contrário, a mesma vislumbra uma adesão interior, através da qual os hábitos individuais e coletivos associados a uma certa orientação da vontade de cada um, são aceitos como válidos para a atividade escolar. É aceitável a ideia de que a coerção externa provoque muitas vezes uma disciplina irreal, já que muitas vezes tal coerção não possui base na vida interior do sujeito.

Dessa forma, a disciplina dentro da escola acaba por ser um agrupamento de normas que devem ser respeitadas para a eficácia da aprendizagem, isto é, ela configura-se numa qualidade de relacionamento pessoal estabelecido entre os professores e alunos dentro da sala de aula e, por conseguinte, na escola.

$\mathrm{Na}$ disciplina, como em todo relacionamento pessoal, é preciso considerar a posição de todos os envolvidos, portanto deve-se levar em conta as formas de ser do professor e do aluno, bem como as características do ambiente.

No passado, o aluno que fazia tudo que o professor e o diretor mandavam era visto como disciplinado. Já se considerava dantes que a disciplina fosse um agrupamento 
de normas para o bom funcionamento do ensino, entretanto com um viés diferenciado, ou seja, além de respeitar tais normas, o aluno disciplinado era tido como aquele que não questionava e aceitava passivamente as ordens dadas. Assim, a concepção de disciplina opunha-se ao respeito à personalidade individual do aluno.

Opondo-se a essa concepção, muitos professores, por várias vezes precipitaram-se equivocadamente ao outro extremo, sendo permissivos demais, e assim substituindo o exagero das ordens pelo exagero de liberdade.

Sobre esse aspecto, acredita-se que na escola deve existir conjuntamente a disciplina e a liberdade, sendo que esta última, englobe o senso de responsabilidade.

Sabe-se que a vida em sociedade impõe o desenvolvimento e o cumprimento de regras capazes de direcionar as relações, facilitar a cooperação e o diálogo, bem como a troca de experiências entre os membros da sociedade. Sob tal ótica, a escola necessita de normas e preceitos orientadores do seu funcionamento e das relações pessoais entre os elementos que nela estão presentes. Assim, as regras abandonam o contorno castrador que Ihe foi atribuído, para ser concebida como condição sine qua non à boa convivência social. Sendo o professor, dentro desse contexto, o mediador que educa, oferece o exemplo e coloca limites.

Com relação à indisciplina e ao fazer escolar, a intervenção do professor é fundamental para que as interações sociais que acontecem na sala de aula façam parte da formação de todos os que dela participam. É importante fornecer aos alunos referencias que possibilitem uma relação de confiança e respeito mútuo para que as questões afetivas, emocionais, presentes no processo de aprendizagem, possam ser discutidas e ressignificadas.

E o gestor escolar deve também fazer intervenções no sentido de articular seu conhecimento teórico com sua prática, proporcionando à comunidade/equipe escolar meios de reflexões e ações efetivas para o entendimento da conjuntura disciplinar em um âmbito mais científico, procurando trazer à luz uma atmosfera favorável para 
sugestões, que assumirão um caráter cooperativo e compromissado na busca de alternativas para sanar o problema de disciplina na escola.

\section{REFERENCIAS}

ATTA, Dilza. O acompanhamento pedagógico do trabalho escolar. Revista de Educação/CEAP. Salvador: Centro de Estudos e Assessoria Pedagógica. ano 8, n. $31,2000$.

CARITA, A.; FERNANDES, G. Indisciplina na sala de aula: Como prevenir? Como remediar? Lisboa: Presença, 1997.

DAMON, Willian. Folha de São Paulo. 26 mar. 1995.

ESTRELA, M. T. Relação pedagógica, disciplina e indisciplina na aula. 3. ed. Portugal: Porto, 1992.

FRANCO, Luiz Antônio Carvalho. Problemas de educação escolar. São Paulo, Mec. 1998.

GLATTER, Ron. A gestão como meio de inovação e mudança nas escolas. In: As Organizações Escolares em Análise. Coordenação de António Nóvoa. Lisboa: Publicações Dom Quixote, 1995.

KRUPPA, Sônia M. Postella. Sociologia da Educação. São Paulo. Cortez.1994.

LA TAILLE, Y. Autoridade e limite. Jornal da Escola da Vida. São Paulo, 1994.

MACEDO, Lino de. Fala, Mestre! . Disciplina é um conteúdo como qualquer outro. Entrevista a Marcio Ferrari -Revista Nova Escola. 183. Ed. São Paulo: Ed. Abril, jun/jul/2005.

MESQUITA, Maria Fernanda Nogueira. Valores humanos na educação: uma nova prática na sala de aula. São Paulo. Editora Gentil. 2003. 
TIBA, Içami. Disciplina “O limite na medida certa”. São Paulo. Editora Gente. 1996.

É preciso ter autoridade. In: Edição Especial Veja, nº 24, agosto 2003.

VASCONCELOS, Celso S. Os desafios da indisciplina em sala de aula e na escola. Disponível em: <http://www.celsovasconcellos.com.br/Textos/indi.pdf > Acesso em: 15 ago. 2018.

Enviado: Junho, 2019.

Aprovado: Outubro, 2019. 